\title{
Immunoinformatics and analysis of antigen distribution of Ureaplasma diversum strains isolated from different Brazilian states
}

\author{
Manoel Neres Santos Junior ${ }^{1,2}$, Ronaldo Silva Santos ${ }^{1}$, Wanderson Souza Neves ${ }^{1}$, Janaina Marinho Fernandes ${ }^{1}$, \\ Bruna Carolina de Brito Guimarães², Maysa Santos Barbosa ${ }^{3}$, Lucas Santana Coelho Silva², Camila Pacheco Gomes², \\ Izadora Souza Rezende ${ }^{3}$, Caline Novaes Teixeira Oliveira ${ }^{1,2}$, Nayara Silva de Macêdo Neres ${ }^{1}$, \\ Guilherme Barreto Campos ${ }^{1}$, Bruno Lopes Bastos ${ }^{1}$, Jorge Timenetsky ${ }^{3}$ and Lucas Miranda Marques ${ }^{1,2,3^{*}}$ (D)
}

\begin{abstract}
Background: Ureaplasma diversum has numerous virulence factors that contribute to pathogenesis in cattle, including Lipid-associated membrane proteins (LAMPS). Therefore, the objectives of this study were to evaluate in silico important characteristics for immunobiological applications and for heterologous expression of 36 LAMPs of $U$. diversum (UdLAMPs) and, also, to verify by conventional PCR the distribution of these antigens in strains of Brazilian states (Bahia, Minas Gerais, São Paulo, and Mato Grosso do Sul). The Manatee database was used to obtain the gene and peptide sequences of the antigens. Similarity and identity studies were performed using BLASTp and direct antigenicity was evaluated by the VaxiJen v2.0 server. Epitope prediction for B lymphocytes was performed on the BepiPred v2.0 and CBTOPE v1.0 servers. NetBoLApan v1.0 was used to predict CD8 ${ }^{+}$T lymphocyte epitopes. Subcellular location and presence of transmembrane regions were verified by the software PSORTb V3.0.2 and TMHMM V2.2 respectively. SignalP v5.0, SecretomeP v2.0, and DOLOP servers were used to predict the extracellular excretion signal. Physico-chemical properties were evaluated by the web-software ProtParam, Solpro, and Protein-sol.

Results: In silico analysis revealed that many UdLAMPs have desirable properties for immunobiological applications and heterologous expression. The proteins gudiv_61, gudiv_103, gudiv_517, and gudiv_681 were most promising. Strains from the 4 states were PCR positive for antigens predicted with immunogenic and/or with good characteristics for expression in a heterologous system.

Conclusion: These works contribute to a better understanding of the immunobiological properties of the UdLAMPs and provide a profile of the distribution of these antigens in different Brazilian states.
\end{abstract}

Keywords: Ureaplasma diversum, Immunoinformatics, Lipoproteins, Prediction

\footnotetext{
* Correspondence: Imirandamarques@gmail.com

'Department of Biointeraction, Multidisciplinary Institute of Health,

Universidade Federal da Bahia, Rua Hormindo Barros, 58 - Quadra 17 - Lote

58, Bairro Candeias - CEP: 45.029-094, Vitória da Conquista, BA, Brazil

${ }^{2}$ Department of Microbiology, State University of Santa Cruz (UESC), Ilhéus,

Brazil

Full list of author information is available at the end of the article
}

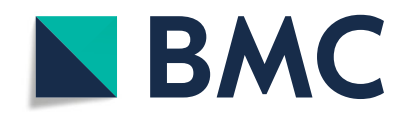

(c) The Author(s). 2020 Open Access This article is licensed under a Creative Commons Attribution 4.0 International License, which permits use, sharing, adaptation, distribution and reproduction in any medium or format, as long as you give appropriate credit to the original author(s) and the source, provide a link to the Creative Commons licence, and indicate if changes were made. The images or other third party material in this article are included in the article's Creative Commons licence, unless indicated otherwise in a credit line to the material. If material is not included in the article's Creative Commons licence and your intended use is not permitted by statutory regulation or exceeds the permitted use, you will need to obtain permission directly from the copyright holder. To view a copy of this licence, visit http://creativecommons.org/licenses/by/4.0/. The Creative Commons Public Domain Dedication waiver (http://creativecommons.org/publicdomain/zero/1.0/) applies to the data made available in this article, unless otherwise stated in a credit line to the data. 


\section{Background}

$U$. diversum, a member of the Mollicutes class, is a bovine pathogen related to reproductive disorders [1]. This agent presents the following outstanding characteristics: the production of ammonia, through urea hydrolysis, and the absence of a cell wall [2]. Although $U$. diversum infection is not conditioned by the presence of clinical symptoms, it can colonize the respiratory and genital/reproductive systems of cattle, generating severe inflammatory conditions often culminating in abortion [3]. It is considered an opportunistic pathogen found in the mucosa and secretions of the vulva, vagina, and udder of cows and secretion of the respiratory tract of calves [1].

Milk production in cows and spermatogenesis in bulls are also affected. $U$. diversum produces mastitis along with visible changes in the milk and udder [4]. In bulls, it causes seminal vesiculitis, balanoposthitis, epididymitis, and morphological and functional changes in sperm. Thus, $U$. diversum colonizes different regions of the reproductive system leading to active semen contamination [5]. Infection of semen for artificial insemination and in vitro fertilization results in serious obstacles to modern bovine reproduction techniques [6].

In addition to urease, $U$. diversum has sophisticated virulence mechanisms, including LAMPs, a mixture of mycoplasmic lipoproteins expressed on the cell surface that interact directly with host cells. These antigens are considered the main molecular agents associated with pathogens in several Mollicutes species and play an important role in host pathogenicity and immunomodulation [7]. In addition to lipoproteins, in the bovine ureaplasma genome, our research group identified genes encoding the multiple band antigen (MBA), which contain multiple series repetitions in the $\mathrm{C}$-terminal region, as well as the gene for hemolysin and for the Mycoplasma Ig binding protein (MIB) and Mycoplasma Ig protease (MIP) -MIB-MIP system-, which acts by binding and cleaving the IgG heavy chain $[2,8]$.

The genomic sequencing of a species offers researchers new possibilities for research. Rapid analysis of all or part of the genome allows the construction of primers and screening of genes coding for virulence factors in the most diverse bacterial strains. The use of immunoinformatics tools allows screening with a high level of reliability of the physico-chemical and immunological properties of these molecules with low cost and reliable results [9]. The use of recombinant DNA technology can, through expression in a heterologous system, allow the analysis of virulence factors alone. Therefore, the objective of this work was to evaluate antigens of $U$. diversum regarding immunobiological properties and desirable characteristics for expression in a heterologous system, as well as to evaluate the distribution of these antigens in isolates from different regions of Brazil.

\section{Results}

$U$. diversum antigens have low similarity with bovine proteome proteins

BLASTp analyses of the 36 UdLAMPs with bovine proteomes revealed that the maximum similarity occurred between the lipoprotein gudiv_159 and the Tinken-1 protein from Bos taurus taurus (29\%). Bos taurus indicus had a similarity detected only for gudiv_517 (10\%). The hybrid showed no significant similarity to any protein (Table 1).

\section{In silico analysis showed that $U$. diversum antigens have} epitopes for B and T lymphocytes

Conformational and linear B cell epitopes were evaluated for the number of regions and the total percentage of amino acids in epitope regions. All proteins showed conformational epitopes for B lymphocytes. The most significant B cell epitopes are listed in Additional Table 1. The number of antigenic regions ranged from 2 in gudiv_388 to 124 in gudiv_398. The proteins with the lowest and highest percentage of amino acids in antigenic regions were gudiv_164 (4.3\%) and gudiv_66 (39.9\%) respectively (Table 2). Except for 10 proteins (gudiv_546, gudiv_457, gudiv_427, gudiv_442, gudiv_ 388, gudiv_357, gudiv_331, gudiv_228, gudiv_171 and gudiv_159), all the others have a number of predicted regions greater than or equal to the values for surface protein 5 (Msp5) from Anaplasma marginale (Table 3). In the prediction of linear epitopes the number of antigenic regions varied from 1 in gudiv_159 to 84 in gudiv_398. The protein with the highest percentage of amino acids in antigenic regions was gudivi_179 (90.4\%). Thirty proteins had number of antigenic regions greater than or equal to Msp5. Eighteen of the 36 UdLAMPs were predicted to be antigenic (score greater than or equal to 0.5 on the VaxiJen server).

In the prediction for major histocompatibility complex class I (MHCI) ligand, with the exception of gudiv_85 and gudiv_159, all other lipoproteins showed at least one predicted link for 4 of the $8 \mathrm{MHCI}$ alleles bovine lymphocyte antigen (BoLA) studied (Table 3). Epitopes with strong binding in each BoLA allele are listed in Additional Tables 2 and 3. The maximum number of bonds was between the epitopes of the gudiv_398 protein and the BoLA-2 201201 allele (75 bonds). Only three $U$. diversum antigens (gudiv_85, gudiv_331, and gudiv_388) had fewer connections than the Theileria parva 2 antigen (Tp2) in all alleles, of these, gudiv_85 did not show predicted connections in any allele (Table 3 ).

\section{Some UdLAMPs have low identity compared to proteomes of other Mollicutes}

The identity analysis of UdLAMPs with proteomes of other Mollicutes (Mycoplasma bovis, Mycoplasma 
Table 1 Analysis of similarity between sequences of 36 UdLAMPs and proteomes of bovine subspecies (Bos taurus taurus, Bos taurus indicus and the hybrid Bos taurus $x$ Bos indicus) performed using the BLASTp tool

\begin{tabular}{|c|c|c|c|}
\hline \multirow[t]{2}{*}{ UdLAMPs } & \multicolumn{3}{|c|}{ Similarity with different bovine proteomes ${ }^{b}$} \\
\hline & Bos taurus taurus & Bos taurus indicus & Hybrid $^{2}$ \\
\hline gudiv_61 & - & - & - \\
\hline gudiv_66 & - & - & - \\
\hline gudiv_85 & - & - & - \\
\hline gudiv_91 & $11 \%$ & - & - \\
\hline gudiv_93 & $7 \%^{\mathrm{a}}$ & - & - \\
\hline gudiv_103 & - & - & - \\
\hline gudiv_159 & $29 \%$ & - & - \\
\hline gudiv_162 & - & - & - \\
\hline gudiv_164 & - & - & - \\
\hline gudiv_171 & $9 \%$ & - & - \\
\hline gudiv_179 & - & - & - \\
\hline gudiv_180 & $4 \%$ & - & - \\
\hline gudiv_228 & - & - & - \\
\hline gudiv_262 & - & - & - \\
\hline gudiv_287 & $10 \%$ & - & - \\
\hline gudiv_331 & - & - & - \\
\hline gudiv_357 & - & - & - \\
\hline gudiv_388 & - & - & - \\
\hline gudiv_398 & - & - & - \\
\hline gudiv_402 & - & - & - \\
\hline gudiv_410 & - & - & - \\
\hline gudiv_412 & - & - & - \\
\hline gudiv_427 & - & - & - \\
\hline gudiv_442 & - & - & - \\
\hline gudiv_457 & $17 \%$ & - & - \\
\hline gudiv_458 & - & - & - \\
\hline gudiv_499 & - & - & - \\
\hline gudiv_517 & - & $10 \%$ & - \\
\hline udiv_546 & - & - & - \\
\hline gudiv_560 & - & - & - \\
\hline gudiv_633 & $8 \%$ & - & - \\
\hline gudiv_635 & - & - & - \\
\hline gudiv_663 & - & - & - \\
\hline gudiv_680 & - & - & - \\
\hline gudiv_681 & - & - & - \\
\hline gudiv_759 & - & - & - \\
\hline
\end{tabular}

ahybrid: Bos taurus taurus $x$ Bos taurus indicus

${ }^{b}$ Only the maximum similarity found

- Similarity not significant by BLASTp canadense, Mycoplasma bovigenitalium, Mycoplasma bovirhinis and Mycoplasma dispar) revealed that only 8 proteins (gudiv_103, gudiv_159, gudiv_171, gudiv_228, gudiv_517, gudiv_546, gudiv_680, gudiv_681) did not present a significant identity with the analyzed proteomes. Twenty-four proteins showed an identity greater than $30 \%$ (Table 4 ).

\section{Some UdLAMPs have characteristics for heterologous expression in Escherichia coli}

Parameters such as molecular weight (PM), instability index, aliphatic index, grand average of hydropathy (GRAVY), and solubility were predicted for $U$. diversum antigens. The protein PM varied between 9.0 and 240.2 (kilodalton) $\mathrm{kDa}$. The proteins with the highest molecular weight were gudiv_398 $(240.2 \mathrm{kDa})$, gudiv_162 $(90.5 \mathrm{kDa})$ and gudiv_180 $(88.7 \mathrm{kDa})$, while with lower molecular weight were gudiv_159, gudiv 85 , and gudiv_331 with $13.3 ; 9.4$ and $9.0 \mathrm{kDa}$ (Table 5). The instability rates ranged from 9.16 (gudiv_499) to 67.15 (gudiv_331). In general, when this index is less than 40, proteins are considered stable; therefore, in this study, only 4 proteins (gudiv 93, gudiv_159, gudiv_331, and gudiv_560) were classified as unstable according to the prediction. To assess hydrophobicity, GRAVY was studied, GRAVY positive proteins were only gudiv_91, gudiv_228, gudi_357, and gudivi_546 with values of $0.05 ; 0.12 ; 0.61$ and 0.05 , respectively. As for solubility, the proteins gudiv_91, gudiv_171, gudiv_287, gudv_357, gudiv_458, and gudiv_560 were insoluble in both Protein-Sol and SOLpro. Gudiv_91 and gudiv_357 also presented 4 and 7 transmembrane loops, respectively (Table 5). In total, sixteen proteins were predicted to be soluble in the two predictors (Table 5).

\section{A considerable number of UdLAMPs have a signal for excretion by the classical and non-classical pathways} The analysis of classical secretion mediated by signal peptide (SP) was performed by SignalP5. This server predicted SP in 29 of the 36 proteins studied. The size of the SPs ranged from 18 to 29 amino acids and all showed a cleavage site for peptidase II (sec / SPII). A cysteine immediately after the cleavage site can be seen in the predicted SPs (Table 6). The DOLOP server, which uses a series of criteria to predict bacterial lipoprotein SPs, including the preferred occurrence of amino acids, ranked 17 of the 29 proteins predicted by SignalP with typical SP lipoprotein carriers. Of the twentynine proteins predicted with the presence of SPs by SignalP, twenty-five also showed a prediction of non-classical excretion when submitted to the predictor SecretomeP (non-signal peptide-mediated 
Table 2 Prediction of antigenicity and discontinuous and continuous B lymphocyte epitopes of each UdLAMP by the predictors CBTOPE v1.0, BepiPred v2.0, and VaxiJen v2. 0

\begin{tabular}{|c|c|c|c|c|c|}
\hline \multirow[t]{2}{*}{ UdLAMPs } & \multicolumn{2}{|c|}{$\begin{array}{l}\text { conformational epitopes } \\
\text { (CBTOPE) }\end{array}$} & \multicolumn{2}{|l|}{$\begin{array}{l}\text { linear epitopes } \\
\text { (BepiPred) }\end{array}$} & \multirow[t]{2}{*}{$\begin{array}{l}\text { antigenicity } \\
\text { (VaxiJen) }\end{array}$} \\
\hline & $\begin{array}{l}\text { number of predicted } \\
\text { regions }\end{array}$ & $\begin{array}{l}\% \text { of aa in predicted } \\
\text { regions }\end{array}$ & $\begin{array}{l}\text { number of predicted } \\
\text { regions }\end{array}$ & $\begin{array}{l}\% \text { of aa in predicted } \\
\text { regions }\end{array}$ & \\
\hline gudiv_61 & 33 & 23.0 & 9 & 61.6 & 0.54 \\
\hline gudiv_66 & 34 & 39.9 & 15 & 56 & 0.45 \\
\hline gudiv_85 & 42 & 26.3 & 15 & 65.5 & 0.91 \\
\hline gudiv_91 & 19 & 16.7 & 11 & 31 & 0.43 \\
\hline gudiv_93 & 41 & 18.2 & 8 & 88.5 & 0.71 \\
\hline gudiv_103 & 20 & 25.1 & 6 & 68.2 & 0.51 \\
\hline gudiv_159 & 10 & 20.2 & 1 & 83.1 & 1.13 \\
\hline gudiv_162 & 69 & 37.0 & 19 & 73 & 0.48 \\
\hline gudiv_164 & 58 & 4.3 & 7 & 64.6 & 0.55 \\
\hline gudiv_171 & 17 & 16.6 & 14 & 57.6 & 0.31 \\
\hline gudiv_179 & 33 & 31.4 & 4 & 90.4 & 1.1 \\
\hline gudiv_180 & 68 & 27.3 & 25 & 66.5 & 0.54 \\
\hline gudiv_228 & 10 & 9.4 & 11 & 47.3 & 0.48 \\
\hline guduv_262 & 21 & 17.8 & 4 & 77.3 & 0.48 \\
\hline gudiv_287 & 55 & 30.3 & 12 & 73.1 & 0.51 \\
\hline gudiv_331 & 4 & 6.1 & 2 & 62.6 & 1.23 \\
\hline gudiv_357 & 15 & 13.7 & 10 & 36.7 & 0.56 \\
\hline gudiv_388 & 2 & 8.2 & 3 & 58.8 & 0.45 \\
\hline gudiv_398 & 124 & 19.2 & 84 & 55.9 & 0.41 \\
\hline gudiv_402 & 29 & 20.7 & 13 & 62.2 & 0.77 \\
\hline gudiv_410 & 34 & 19.6 & 18 & 61 & 0.48 \\
\hline gudiv_412 & 36 & 15.7 & 16 & 61.6 & 0.5 \\
\hline gudiv_427 & 11 & 21.4 & 6 & 61 & 0.37 \\
\hline gudiv_442 & 13 & 14.1 & 9 & 68.9 & 0.45 \\
\hline gudiv_457 & 13 & 18.6 & 9 & 39.8 & 0.34 \\
\hline gudiv_458 & 36 & 26.9 & 20 & 110 & 0.49 \\
\hline gudiv_499 & 23 & 20.1 & 15 & 59.1 & 0.53 \\
\hline gudiv_517 & 19 & 21.0 & 5 & 63.3 & 0.58 \\
\hline gudiv_546 & 13 & 19.0 & 4 & 59.2 & 0.29 \\
\hline gudiv_560 & 32 & 17.2 & 17 & 59.2 & 0.48 \\
\hline gudiv_633 & 24 & 14.0 & 17 & 63.2 & 0.48 \\
\hline gudiv_635 & 34 & 23.9 & 21 & 59.3 & 0.41 \\
\hline gudiv_663 & 51 & 26.9 & 21 & 57.5 & 0.58 \\
\hline guduv_680 & 23 & 15.7 & 18 & 54.1 & 0.57 \\
\hline gudiv_681 & 25 & 31.6 & 6 & 77.4 & 0.58 \\
\hline gudiv_759 & 47 & 32.1 & 17 & 65.1 & 0.47 \\
\hline Msp5 $^{a}$ & 19 & 45.2 & 5 & 43.3 & 0.51 \\
\hline
\end{tabular}

*Mapping of B lymphocyte epitopes and antigenicity prediction was also performed for the Msp5 ESXA_MYCBO peptide from A. marginale

excretion). In addition, some proteins (gudiv_61, and gudiv_663) not discriminated as having SP for gudiv_93, gudiv_162, gudiv_164, gudiv_179, gudiv_ lipoproteins by DOLOP were predicted to be se287, gudiv_331, gudiv_388, gudiv_546, gudiv_633, creted by non-classic pathways (Table 6). 
Table 3 Prediction of binding of UdLAMPs (peptide windows with 9 amino acids) to different BoLA alleles (MHCI) performed through the NetBoLApan v1.0 server. The total of strong and weak connections is expressed in absolute numbers

\begin{tabular}{|c|c|c|c|c|c|c|c|c|}
\hline UdLAMPs & $\begin{array}{l}\text { BoLA-1 } \\
* 02301\end{array}$ & $\begin{array}{l}\text { BoLA-3 } \\
* 00201\end{array}$ & $\begin{array}{l}\text { BoLA-2 } \\
{ }^{*} 01201\end{array}$ & $\begin{array}{l}\text { BoLA-6 } \\
* 01301\end{array}$ & $\begin{array}{l}\text { BoLA-3 } \\
* 00101\end{array}$ & $\begin{array}{l}\text { BoLA-6* } \\
04101\end{array}$ & $\begin{array}{l}\text { BoLA- } \\
\text { T2C }\end{array}$ & $\begin{array}{l}\text { BoLA - } \\
\text { T5 }\end{array}$ \\
\hline gudiv_61 & 6 & 5 & 9 & 6 & 5 & 3 & 4 & 3 \\
\hline gudiv_66 & 11 & 9 & 8 & 7 & 5 & 5 & 9 & 16 \\
\hline gudiv_85 & 0 & 0 & 0 & 0 & 0 & 0 & 0 & 0 \\
\hline gudiv_91 & 7 & 7 & 9 & 9 & 11 & 0 & 19 & 10 \\
\hline gudiv_93 & 6 & 3 & 12 & 6 & 2 & 10 & 4 & 5 \\
\hline gudiv_103 & 4 & 5 & 7 & 3 & 2 & 5 & 3 & 3 \\
\hline gudiv_159 & 3 & 0 & 7 & 1 & 0 & 0 & 0 & 0 \\
\hline gudiv_162 & 15 & 8 & 24 & 9 & 8 & 13 & 10 & 13 \\
\hline gudiv_164 & 4 & 2 & 3 & 10 & 2 & 4 & 9 & 3 \\
\hline gudiv_171 & 6 & 8 & 10 & 5 & 5 & 4 & 16 & 11 \\
\hline gudiv_179 & 1 & 4 & 12 & 3 & 3 & 3 & 2 & 1 \\
\hline gudiv_180 & 9 & 6 & 26 & 9 & 4 & 17 & 13 & 13 \\
\hline gudiv_228 & 5 & 5 & 4 & 11 & 2 & 9 & 6 & 8 \\
\hline gudiv_262 & 0 & 1 & 3 & 1 & 2 & 4 & 4 & 0 \\
\hline gudiv_287 & 10 & 9 & 26 & 10 & 12 & 14 & 19 & 12 \\
\hline gudiv_331 & 3 & 0 & 5 & 1 & 0 & 1 & 0 & 0 \\
\hline gudiv_357 & 8 & 10 & 3 & 10 & 5 & 7 & 12 & 13 \\
\hline gudiv_388 & 2 & 0 & 4 & 1 & 1 & 1 & 1 & 1 \\
\hline gudiv_398 & 42 & 33 & 75 & 44 & 28 & 34 & 60 & 57 \\
\hline gudiv_402 & 5 & 2 & 8 & 5 & 1 & 6 & 5 & 1 \\
\hline gudiv_410 & 6 & 7 & 17 & 8 & 4 & 6 & 12 & 10 \\
\hline gudiv_412 & 6 & 8 & 13 & 11 & 4 & 9 & 13 & 11 \\
\hline gudiv_427 & 3 & 4 & 3 & 2 & 2 & 3 & 7 & 3 \\
\hline gudiv_442 & 5 & 3 & 6 & 6 & 2 & 4 & 9 & 7 \\
\hline gudiv_457 & 7 & 1 & 7 & 8 & 3 & 7 & 6 & 7 \\
\hline gudiv_458 & 6 & 6 & 20 & 11 & 7 & 3 & 18 & 6 \\
\hline gudiv_499 & 6 & 5 & 11 & 6 & 3 & 6 & 6 & 7 \\
\hline gudiv_517 & 5 & 5 & 8 & 6 & 2 & 3 & 9 & 6 \\
\hline gudiv_546 & 5 & 2 & 6 & 3 & 0 & 3 & 5 & 3 \\
\hline gudiv_560 & 8 & 9 & 12 & 10 & 5 & 14 & 15 & 9 \\
\hline gudiv_633 & 5 & 5 & 13 & 7 & 0 & 9 & 17 & 11 \\
\hline gudiv_635 & 4 & 6 & 16 & 6 & 3 & 9 & 8 & 8 \\
\hline gudiv_663 & 8 & 12 & 16 & 11 & 8 & 7 & 16 & 10 \\
\hline gudiv_680 & 8 & 5 & 16 & 5 & 5 & 7 & 13 & 6 \\
\hline gudiv_681 & 6 & 1 & 6 & 1 & 3 & 2 & 5 & 3 \\
\hline gudiv_759 & 6 & 7 & 10 & 8 & 8 & 9 & 16 & 8 \\
\hline $\operatorname{tp} 2^{*}$ & 5 & 3 & 6 & 7 & 2 & 5 & 9 & 4 \\
\hline
\end{tabular}

* Mapping of TCD8+ lymphocyte epitopes was also performed for Theileria parva Tp2 antigen

The prediction analysis reveals that UdLAMPs have important characteristics both for immunobiological applications and for expression in a heterologous system The antigens of $U$. diversum have been classified according to undesirable properties for use in prophylactic and immunodiagnostic measures; and undesirable properties for expression in E. coli. The proteins gudiv_61, gudiv_ 103, gudiv_517, and gudiv_681 passed in all parameters, not being retained in any exclusion criteria established in this study Fig. 1. In addition, a considerable number 
Table 4 BLASTp identity analysis of 36 UdLAMPs with proteomes of M. bovis, M. canadense, M. bovigenitalium, M. bovirhinis and M.

\begin{tabular}{|c|c|c|c|c|c|}
\hline UdLAMPS & Mycoplasma bovis & Mycoplasma canadense & Mycoplasma bovigenitalium & Mcoplasma bovirhinis & Mycoplasma dispar \\
\hline gudiv_061 & $29.81 \%$ & - & $33.42 \%$ & - & - \\
\hline gudiv_066 & - & - & $26.25 \%$ & - & - \\
\hline gudiv-091 & $29.87 \%$ & $30.03 \%$ & $24.92 \%$ & $26.97 \%$ & - \\
\hline gudiv_085 & - & - & - & $31.91 \%$ & - \\
\hline gudiv_093 & $36.43 \%$ & $30.3 \%$ & $29.4 \%$ & $26.97 \%$ & $28.92 \%$ \\
\hline gudiv_103 & - & - & - & - & - \\
\hline gudiv_159 & - & - & - & - & - \\
\hline gudiv_162 & $43.95 \%$ & $44.93 \%$ & $45.84 \%$ & $77.42 \%$ & $35.01 \%$ \\
\hline gudiv_164 & - & - & $76.92 \%$ & $44.64 \%$ & - \\
\hline gudiv_171 & - & - & - & - & - \\
\hline gudiv_179 & - & $34.38 \%$ & - & - & - \\
\hline gudiv_180 & $45.88 \%$ & $42.65 \%$ & $41.83 \%$ & $29.85 \%$ & $36.36 \%$ \\
\hline gudiv_228 & - & - & - & - & - \\
\hline Gudiv_262 & $29.3 \%$ & - & - & - & - \\
\hline gudiv_287 & $39.77 \%$ & $50 \%$ & $55.56 \%$ & $60.26 \%$ & $39.25 \%$ \\
\hline gudiv_331 & $42.42 \%$ & - & - & - & - \\
\hline gudiv-357 & $31.33 \%$ & $27.2 \%$ & $32.93 \%$ & $33.33 \%$ & $27.39 \%$ \\
\hline gudiv_388 & - & - & 43.33 & - & - \\
\hline gudiv_398 & - & $51.4 \%$ & $63.68 \%$ & $29.76 \%$ & $26.36 \%$ \\
\hline gudiv_402 & $43.75 \%$ & - & - & $32.26 \%$ & - \\
\hline gudiv_410 & $54.84 \%$ & - & $40.82 \%$ & - & - \\
\hline gudiv_412 & $51.61 \%$ & $36.67 \%$ & $42.86 \%$ & - & - \\
\hline gudiv_427 & - & - & - & $33.96 \%$ & - \\
\hline gudiv_442 & & $28.79 \%$ & - & - & - \\
\hline gudiv_457 & $31.58 \%$ & $28.32 \%$ & $29.12 \%$ & $28.32 \%$ & $27.59 \%$ \\
\hline gudiv_458 & - & - & $38.03 \%$ & $50 \%$ & - \\
\hline gudiv_499 & - & - & $37.5 \%$ & - & - \\
\hline gudiv_517 & - & - & - & - & - \\
\hline gudiv_546 & - & - & - & - & \\
\hline gudiv_560 & $29.11 \%$ & - & $28.52 \%$ & - & - \\
\hline gudiv_635 & - & - & $47.22 \%$ & - & - \\
\hline gudiv_663 & $54.17 \%$ & - & - & & $33.33 \%$ \\
\hline gudiv_663 & - & - & $46 \%$ & $34.25 \%$ & - \\
\hline gudiv_680 & - & - & - & - & - \\
\hline gudiv_681 & - & - & - & - & - \\
\hline gudiv_759 & $30.66 \%$ & - & - & $27.78 \%$ & $27.98 \%$ \\
\hline
\end{tabular}

${ }^{-}$Identity not significant by BLASTp

of UdLAMPs were retained in only one or none of the exclusion criteria.

Gene coding sequences (CDS) for LAMPs predicted as antigenic are present in strains from different Brazilian states

To verify the distribution of $\mathcal{U}$. diversum antigens in different Brazilian states, the presence of genes for LAMPs in $46 U$. diversum strains was investigated by PCR. Table 7 lists the primers constructed. All antigens were detected in strain ATCC 49782. The lowest and highest percentage of amplified antigens (not considering the ATCC strain) occurred for strains S8 and 59, respectively, 5.6 and $83.3 \%$ (Fig. 2). Regarding antigens, the highest prevalence was gudiv_759, gudiv_357, and gudiv_91 detected in $87,84.8$, and $82.6 \%$ of the strains, 
Table 5 Prediction of physicochemical properties of UdLAMPs. Aliphatic index, PM, GRAVY, and instability index obtained in ProtParam. The solubility was predicted using the server SOLpro and Protein-Sol

\begin{tabular}{|c|c|c|c|c|c|c|}
\hline \multirow[t]{2}{*}{ UdLAMPS } & \multicolumn{4}{|l|}{ PROTPARAM } & \multirow{2}{*}{$\begin{array}{l}\text { Protein- } \\
\text { Sol }\end{array}$} & \multirow[t]{2}{*}{ SOLpro } \\
\hline & Number of amino acids & PM (kDa) & Instability Index & GRAVY & & \\
\hline gudiv_061 & 404 & 45.6 & 24.4 & -0.65 & Soluble & soluble \\
\hline gudiv_066 & 393 & 46.4 & 38.09 & -0.51 & Insoluble & soluble \\
\hline gudiv_085 & 495 & 52.9 & 26.61 & -0.58 & Soluble & soluble \\
\hline gudiv_091 & 462 & 52.4 & 30.08 & 0.05 & Insoluble & insoluble \\
\hline gudiv_093 & 660 & 75.8 & 41.13 & -1.18 & Soluble & soluble \\
\hline gudiv_103 & 220 & 25 & 26.72 & -0.36 & Soluble & soluble \\
\hline gudiv_159 & 124 & 13.3 & 44.69 & -1.4 & Soluble & soluble \\
\hline gudiv_162 & 799 & 90.5 & 33.12 & -0.74 & Soluble & soluble \\
\hline gudiv_164 & 280 & 32.2 & 34.88 & -0.93 & Soluble & insoluble \\
\hline gudiv_171 & 349 & 41.0 & 38.73 & -0.41 & Insoluble & Insoluble \\
\hline gudiv_179 & 408 & 43.8 & 39.13 & -1.16 & Soluble & Soluble \\
\hline gudiv_180 & 774 & 88.7 & 29.23 & -0.74 & Soluble & Soluble \\
\hline gudiv_228 & 224 & 25.9 & 29.91 & 0.12 & Soluble & Insoluble \\
\hline gudiv_262 & 343 & 39.1 & 39.42 & -1.26 & Soluble & Soluble \\
\hline gudiv_287 & 739 & 83.7 & 33.21 & -0.58 & Insoluble & Insoluble \\
\hline gudiv_331 & 99 & 9 & 67.15 & -1.13 & - & Soluble \\
\hline gudiv_357 & 343 & 39 & 35.32 & 0.61 & Insoluble & Insoluble \\
\hline gudiv_388 & 85 & 9.4 & 17.65 & -0.52 & Soluble & Soluble \\
\hline gudiv_398 & 2052 & 240.2 & 28.43 & -0.57 & Insoluble & - \\
\hline gudiv_402 & 381 & 41.9 & 31.04 & -0.72 & Soluble & Soluble \\
\hline gudiv_410 & 454 & 53.6 & 27.91 & -0.73 & Soluble & Insoluble \\
\hline gudiv_412 & 502 & 59.2 & 29.46 & -0.68 & Soluble & Insoluble \\
\hline gudiv_427 & 187 & 22.3 & 20.89 & -0.39 & Soluble & Soluble \\
\hline gudiv_442 & 312 & 36.4 & 29.79 & -0.36 & Soluble & Insoluble \\
\hline gudiv_457 & 204 & 24.2 & 35.81 & -0.37 & Soluble & Insoluble \\
\hline gudiv_458 & 520 & 60.5 & 30.61 & -0.73 & Insoluble & Insoluble \\
\hline gudiv_499 & 318 & 36 & 9.19 & -0.59 & Soluble & Soluble \\
\hline gudiv_517 & 215 & 25 & 27.83 & -0.23 & Soluble & Soluble \\
\hline gudiv_546 & 142 & 16 & 27.89 & 0.05 & Soluble & Insoluble \\
\hline gudiv_560 & 522 & 62.2 & 41.38 & -0.86 & Insoluble & Insoluble \\
\hline gudiv_663 & 573 & 64.3 & 23.08 & -0.43 & Soluble & Insoluble \\
\hline gudiv_633 & 514 & 60.2 & 33.36 & -0.65 & Soluble & Insoluble \\
\hline gudiv_635 & 506 & 59.4 & 27.59 & -0.63 & Soluble & Insoluble \\
\hline gudiv_680 & 434 & 49.6 & 38.43 & -0.58 & Soluble & Insoluble \\
\hline gudiv_681 & 266 & 29.8 & 17.68 & -0.6 & Soluble & Soluble \\
\hline gudiv_759 & 533 & 61.2 & 35.2 & -0.71 & Soluble & Soluble \\
\hline
\end{tabular}

-Results not determined by the predictor

respectively. In contrast, the least present were gudiv $402(2.2 \%)$ and gudiv_458 (4.3\%). The presence of antigens varied in the strains isolated from the states studied (Fig. 3). In Bahia, the state with the highest number of strains, a total of 35 antigens were detected by PCR. The only strain in Minas Gerais tested positive for seven proteins. Isolated representatives of Mato Grosso do Sul (805 and 9653) had 27 antigens. In São Paulo, all 13 strains were PCR positive for 34 proteins. 
Table 6 Prediction of classical secretion of the signal peptide performed in SignalP v5.0 and DOLOP. Prediction of non-classical secretion by SecretomeP v2.0. Subcellular location and number of transmembrane loops predicted in PSORTb V3.0.2 and TMHMM V2.0

\begin{tabular}{|c|c|c|c|c|c|c|}
\hline \multirow[t]{2}{*}{ UdLAMPs } & \multicolumn{3}{|l|}{ SignalP } & \multicolumn{3}{|c|}{ Subcellular Location } \\
\hline & Peptide signal and clevage site & Type & SecretomeP & TMHMM & PSortb & DOLOP \\
\hline gudiv_061 & MRKHKRIALATGLVAGLLATVSWAVA--CN & $\mathrm{Sec} / \mathrm{SP} \|$ & Yes & 1 & Unknown & - \\
\hline gudiv_066 & MKPNHSAGWLFKSKWFFALTSFSIISVALVVS--CH & $\mathrm{Sec} / \mathrm{SP} \|$ & Yes & 0 & Unknown & Lipoprotein \\
\hline gudiv_085 & MKIKKIKYKWMSLAIATTVAAAGISAVLIS--CT & $\mathrm{Sec} / \mathrm{SP} \|$ & Yes & 1 & Unknown & Lipoprotein \\
\hline gudiv_091 & - & - & - & 4 & Plasma membrane & - \\
\hline gudiv_093 & - & $\mathrm{Sec} / \mathrm{SP} \|$ & Yes & 0 & Unknown & - \\
\hline gudiv_103 & MFKTKRAKLTVGLLTWGLITTPLIISS--CS & $\mathrm{Sec} / \mathrm{SP} \|$ & Yes & 1 & Unknown & Lipoprotein \\
\hline gudiv_159 & MVSTILIGSSIVAVAAA—CN & $\mathrm{Sec} / \mathrm{SP} \|$ & - & 0 & Unknown & - \\
\hline gudiv_162 & MKKVINKKWLGLIVGSVFVLSATAAVAAS--CN & $\mathrm{Sec} / \mathrm{SP} \|$ & Yes & 1 & Unknown & - \\
\hline gudiv_164 & MTKKKWYSLIAGLWGSVPASILIA—CS & $\mathrm{Sec} / \mathrm{SP} \|$ & Yes & 1 & Unknown & - \\
\hline gudiv_171 & - & - & - & 0 & Unknown & - \\
\hline gudiv_179 & MAGVSVIGWAA-CA & $\mathrm{Sec} / \mathrm{SP} \|$ & Yes & 0 & Unknown & - \\
\hline gudiv_180 & MKTKKKVIISALLCSAVLVPIVGLIAS—CN & $\mathrm{Sec} / \mathrm{SP} \|$ & Yes & 1 & Unknown & Lipoprotein \\
\hline gudiv_228 & - & - & - & 1 & Cytoplasm & - \\
\hline gudiv_262 & MIKHKFKNKKLWLLSLGMVAVIGATAILAS--CN & $\mathrm{Sec} / \mathrm{SP} \|$ & Yes & 1 & Plasma membrane & Lipoprotein \\
\hline gudiv_287 & MKKSLFKKELAITLGLASVAIITPIIAIA—CN & Sec/SPII & Yes & 0 & Unknown & - \\
\hline gudiv_331 & MVSTILVGSSIAAIAAA—CN & $\mathrm{Sec} / \mathrm{SP} \|$ & Yes & 0 & Extracellular & - \\
\hline gudiv_357 & - & - & - & 7 & Plasma membrane & - \\
\hline gudiv_388 & MKKFKSKKWVNYGFGLVALVGLSTSLAIA--CS & $\mathrm{Sec} / \mathrm{SP} \|$ & Yes & 1 & Unknown & - \\
\hline gudiv_398 & MKKRSKLIYFAVSTLSLSTIIGSLLIG—CT & $\mathrm{Sec} / \mathrm{SP} \|$ & Yes & 1 & Extracellular & Lipoprotein \\
\hline gudiv_402 & MKRKINKKLILFSSLITLGLSSSIIIAS—CT & Sec/SPII & Yes & 1 & Plasma membrane & Lipoprotein \\
\hline gudiv_410 & NKKLKSTIIFSSLFLVSIPWIAS—CT & $\mathrm{Sec} / \mathrm{SP} \|$ & Yes & 1 & Plasma membrane & Lipoprotein \\
\hline gudiv_412 & NKRLKSTIVFSSLFLVSIPWLAS-CT & $\mathrm{Sec} / \mathrm{SP} \|$ & Yes & 0 & Unknown & Lipoprotein \\
\hline gudiv_427 & VSKTKKKFKLLSSVVLVLGLVAWPTILA-SC & $\mathrm{Sec} / \mathrm{SP} \|$ & - & 1 & Plasma membrane & - \\
\hline gudiv_442 & MKKYQKVLLLSSFLFWAPIVSS—CS & $\mathrm{Sec} / \mathrm{SPI}$ & - & 2 & Unknown & Lipoprotein \\
\hline gudiv_457 & - & - & - & 0 & Unknown & - \\
\hline gudiv_458 & MRKQKRLLIATLISSLWLTPIILAS—CN & $\mathrm{Sec} / \mathrm{SP} \|$ & Yes & 1 & Unknown & Lipoprotein \\
\hline gudiv_499 & MKLKKLHKQILISTSLITTFGLTSLLAA—CH & $\mathrm{Sec} / \mathrm{SP} \|$ & Yes & 0 & Unknown & Lipoprotein \\
\hline gudiv_517 & MKLKHKWLITIGSIGFISIIGFSTLASCS & Sec/SPII & - & 1 & Unknown & Lipoprotein \\
\hline gudiv_546 & MLKKNQIKKMLLITSTSLVSLGIWSAVA--CS & $\mathrm{Sec} / \mathrm{SP} \|$ & Yes & 0 & Unknown & - \\
\hline gudiv_560 & MTKARKILISSFILTTIGSVSVLVAS-CS & $\mathrm{Sec} / \mathrm{SP} \|$ & Yes & 1 & Extracellular & Lipoprotein \\
\hline gudiv_633 & MKINIKFKIMASFLFLSIAPIIAVS-CS & $\mathrm{Sec} / \mathrm{SP} \|$ & Yes & 0 & Plasma membrane & - \\
\hline gudiv_635 & MKRKRIIKQAILIGAVASSISIPLLIAS—CT & Sec/SPII & Yes & 0 & Unknown & Lipoprotein \\
\hline gudiv_663 & MKINIKFKIMASFLFLSIAPIIAVS-CS & $\mathrm{Sec} / \mathrm{SP} \|$ & Yes & 1 & Plasma membrane & - \\
\hline gudiv_680 & MMINIKRKLMMVFLASLSTITVSSLIVA—CS & $\mathrm{Sec} / \mathrm{SP} \|$ & Yes & 0 & Unknown & Lipoprotein \\
\hline gudiv_681 & MKIKRKGIFAFASIGIVAITTTLIAS_CA & $\mathrm{Sec} / \mathrm{SP} \|$ & Yes & 1 & Unknown & Lipoprotein \\
\hline gudiv_759 & - & - & - & 0 & Cytoplasm & - \\
\hline
\end{tabular}

- Not predicted by the predictor

\section{Discussion}

Mollicutes lipoproteins are important virulence factors associated with pathogenesis in the reproductive and respiratory tract of infected hosts [10]. In this study, the lipoprotein gudiv_159 had $29 \%$ similarity with the
Tektin-1 protein from the Bos taurus taurus proteome. For the other UdLAMPs and proteins from other bovine subspecies, all similarity values were less than $12 \%$. Similarity values greater than $25 \%$ are relevant when assessing immunological aspects [11]. The similarity between 


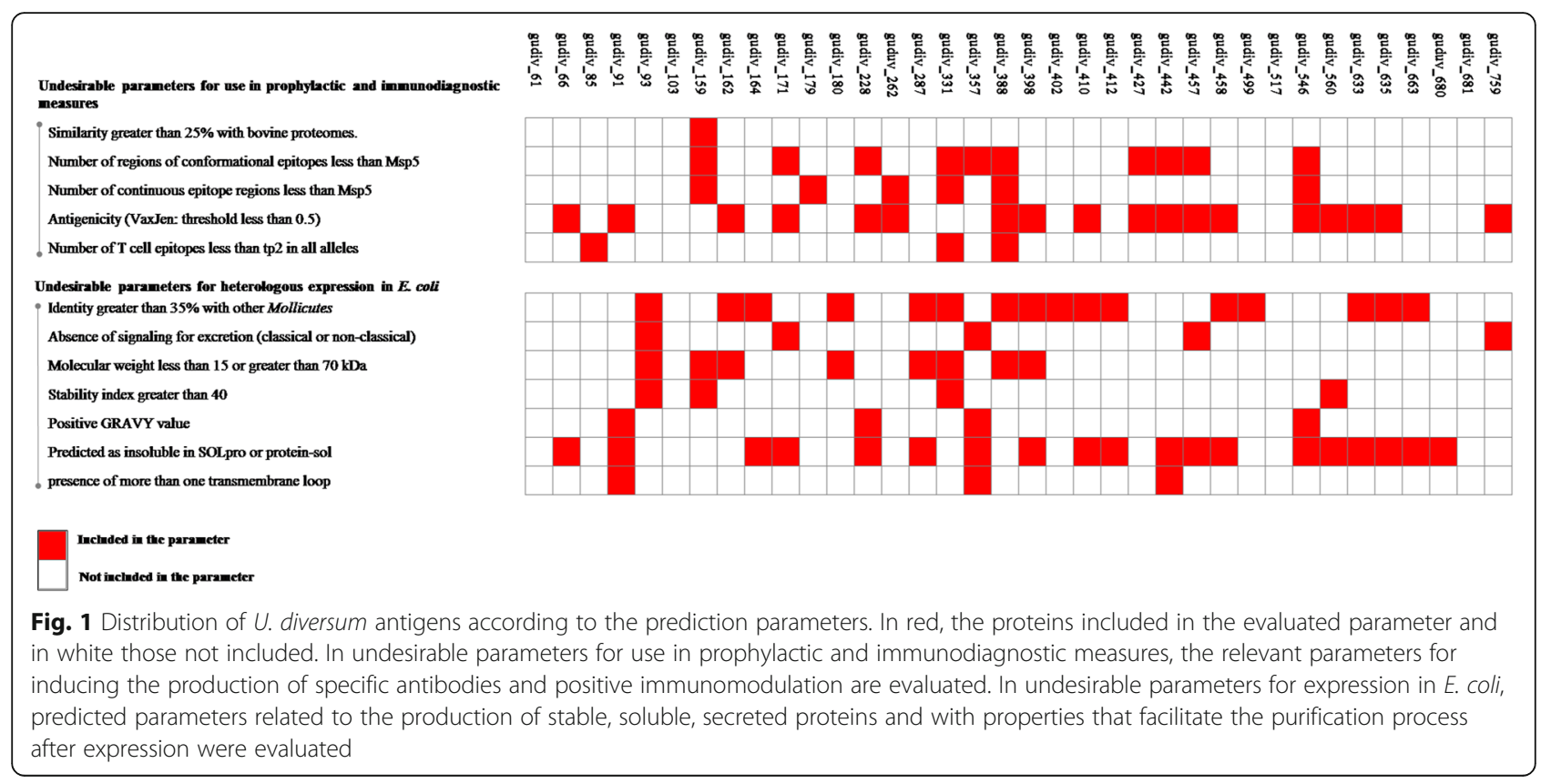

virulence factors and host proteins can make it difficult to develop an adequate immune response, or even generate cross-reaction events with autoantibody production during infection [12]. Mycoplasma hominis, $M$. fermentans and $M$. arthitides are species of Mollicutes often found in patients with autoimmune diseases [10].

A protective immune response with the production of effector cells and antibodies able to recognize epitopes of an infectious agent are essential for fighting infection. Conformational epitopes represent the majority of B cell epitopes (about 90\%). However, conformational epitopes usually contain one or a few stretches of linear epitopes [13]. In the prediction, we found that all 36 UdLAMPs have conformational and linear epitopes for B lymphocytes and are predicted as antigenic (VaxiJen predictor). A considerable number of regions of conformational and linear epitopes were greater than or equal to the values for Msp5, one of the main surface proteins of A. marginale, known for its ability to induce antibody production during cattle infection [14]. The presence of these epitopes points to these molecules as agents capable of stimulating the development of a humoral immunological response.

$U$. diversum can also behave as an optional intracellular pathogen [15]. Thus, the possibility of UdLAMPs being processed and presented via MHCI can lead to cellular response activation. In this study, epitopes binding to bovine $\mathrm{MHCI}$ alleles were predicted in several UdLAMPs. Furthermore, 33 LAMPs had connections equal to or greater than the T. parva $\mathrm{Tp} 2$ antigen in all studied alleles. Tp2 is recognized for stimulating $\mathrm{CD} 8^{+}$ $\mathrm{T}$ cells during bovine $T$. parva infection [16]. The studied alleles represent cattle destined for the different livestock sectors. Five alleles representing Bos taurus taurus (BoLA-6* 01301, BoLA-2 * 01201, BoLA-3 * 00201, BoLA- $1 * 02301$ and BoLA- $6 * 04101)$, two alleles representing Bos taurus indicus (Bola - T5, BoLA-3 * 00101) and an allele (BoLA-T2C) belongs to a hybrid [17]. Taurine breeds are predominantly found on dairy farms and Zebu cattle are mostly used for meat production [18]. Bovine hybrids are usually produced to align the commercial and management characteristics of both subspecies [19]. In this case, our prediction data reveal that a considerable number of UdLAMPs can interact with MHCI alleles of cattle destined for different activities in the livestock sector, reflecting in activation of inactivation immune response.

The identity analysis of UdLAMPs with proteomes of other microorganisms capable of infecting cattle is a useful initial approach for studies aimed at using these antigens or antibodies produced in immunodetection tests. We found that the proteins gudiv_103, gudiv_159, gudiv_171, gudiv_228, gudiv_517, gudiv_546, gudiv_680, and gudiv_681 did not present a significant identity with the proteins of other important Mollicutes that infect bovine. In contrast, 25 proteins showed an identity greater than $30 \%$. According to Rost [20] above a cutoff point of $30 \%$ identity, $90 \%$ of the pairs are homologous. The low identity between proteins of different infectious agents from the same host is related to good specificity when considering detection tests [21]. Thus, $U$. diversum proteins with low identity may represent specific targets for use in immunodiagnostic techniques in detecting this pathogen. 
Table 7 Primers for amplifying UdLAMPs using conventional PCR

\begin{tabular}{|c|c|c|c|}
\hline UdLAMPs & Forward & Reverse & Fragment length (bp) \\
\hline gudiv_061 & CAGTAAGTGTTGTTGCTG & GTTACCGAAGTCTTGTCC & 797 \\
\hline gudiv_066 & AGCGTTGCCTTAGTTAGT & TTAATCCGTCCCACATTG & 965 \\
\hline gudiv_085 & CAGGAAGTGCTACAGTTG & ACTCATCATTTACCACCT TC & 421 \\
\hline gudiv_091 & CTGAAACCGCTITAACAAG & ACAACAAGCCGACTAAATC & 652 \\
\hline \multirow[t]{2}{*}{ gudiv_093 } & GGCTCAAGTAGTGAAGAGAAG & GCAAATGGAATTGGATGTAC & 680 \\
\hline & TTCTGAACCTGAACCACAA & CTAATTCACGACTGCCTT & 937 \\
\hline gudiv_103 & GTACCTAATCTCAATCAAGC & CAACTAAGTCAACACGAG C & 307 \\
\hline gudiv_159 & CACCTAATCCATCAAAGAAC & GTTGTAGTAGAGTTGCCTA & 260 \\
\hline gudiv_162 & CTCAGTAACTACACCACTT & TGCTITACCTGTACGGAAT & 298 \\
\hline gudiv_164 & GTAGTAGGTTCAGTTCCT G & GATCAGAAGATAGCGATCAG & 732 \\
\hline gudiv_171 & CCAGATGGTAATGCTGAAC & CTACTCATGCTCTTAGTTC & 547 \\
\hline gudiv_179 & GCGAAGATCCTAAAGCAAT & CGAACCTGAAGTAATAAGG & 379 \\
\hline gudiv_180 & GCTTGGAAGACAACTCTAA & TTCTAGCACCTCAGGTAG & 930 \\
\hline gudiv_228 & GAGGAACTITAAGTGATCCA & CATGGTTATACAAAGGGGTG & 125 \\
\hline \multirow[t]{2}{*}{ gudiv_262 } & CATTAGGTATGGTTGCTGTA & GTTTGATCGGCTCTTCTG & 252 \\
\hline & CATTAGGTATGGTTGCTG & CTTCTGGCATCGGATTTG & 543 \\
\hline gudiv_287 & TGAGCAACCAAATACTGAAG & GCTTGAGTTGATGTGTTTG & 312 \\
\hline gudiv_331 & GGTAAGCACGATCCTTGT & TTGTTTGCGGCTGAATC & 178 \\
\hline gudiv_357 & GGTAATTGGTGGTGTAATAG & AAGTGATTCAGGAGTTGC & 232 \\
\hline gudiv_388 & CTATGGGTTTGGATTAGT & CTITCTTTAGCAGCTTC & 187 \\
\hline gudiv_398 & CGTTATCAATACCACGACTTC & TGGAATATGTCCTGATCG & 351 \\
\hline gudiv_402 & GGTAGAGGTAGTGGTTCA & AGCAGATGGATCTTCGTAAT & 945 \\
\hline gudiv_410 & CACTAGAACCAGCAAAACC & CCAAAATATCAGTCCGATCAG & 819 \\
\hline gudiv_412 & ACCACTTGTAGCACTAGA & CTAAAATATCAGCCCGATCAG & 830 \\
\hline gudiv_427 & TTAGGATTGGTTGCTGTTG & GATTGTTGTGGGTGAAAATC & 509 \\
\hline gudiv_442 & CTACCAGATAGTATTGCTC & GGTGGACTTGTTAATGTATC & 809 \\
\hline gudiv_457 & CAGAAGAATCACTAGAGC & CTGCTGGGTTATCACTTC & 360 \\
\hline gudiv_458 & CCAACCAACTCCTAAACTAG & GCACTCCAAGTGATTCATC & 482 \\
\hline gudiv_499 & TAATCTTCCAACCCATCAAG & CTTCTTITGCTGTATGAGC & 572 \\
\hline gudiv_517 & AACCAACTITGAGCAAGC & GCTGCTTTAGAAAAGATAG & 321 \\
\hline gudiv_546 & CAGTTGCTTGTTCACAAC & GGCTTGGTTTGGTTCAAA & 266 \\
\hline gudiv_560 & GGATCAGTTAGTGTACTTGTTG & TTAGCAAAGGTTGGATCTTC & 344 \\
\hline gudiv_635 & GCAGTTGCTTCATCTATCT & CTAGTCTTGCTACCTTATC & 607 \\
\hline gudiv_663 & CGCTACAACTATGACTGAT & AATGGCTGACCAAATTGTG & 243 \\
\hline gudiv_663 & CTGATCCTACAGTGGTTAAAC & CCATCAAAGATGAAGTCTTG & 607 \\
\hline gudiv_680 & GACAGAGTCTCCAAAACC & TCTAACTGTTTCTTCATTAGGG & 547 \\
\hline gudiv_681 & GATTAGTTCAAGTGGTGAAG & ATCATCAACAGCAGTCTT G & 346 \\
\hline gudiv_759 & GCTGATGAAGGATATTATGG & GCAAGTGATAGATCGTTTG & 749 \\
\hline
\end{tabular}

${ }^{\mathrm{a}}$ Two pairs of primers were designed for gudiv_93 and gudiv_262

In addition to the prediction of immunobiological properties, the prediction of properties favorable to expression in a heterologous system can contribute to the broad scale of a protein biological target. Some physicochemical properties influence the state of solubility, the formation of inclusion bodies or proteolysis of the heterologous peptide [22]. In this study, the protein PM ranged from 9.0 to $240.2 \mathrm{kDa}$. Proteins with PM between 70 and $60 \mathrm{kDa}$ are well tolerated when E. coli is used as an expression system; however, proteins with very high PM are not adequately expressed in these bacteria, and are, therefore, degraded or structured in the form of 


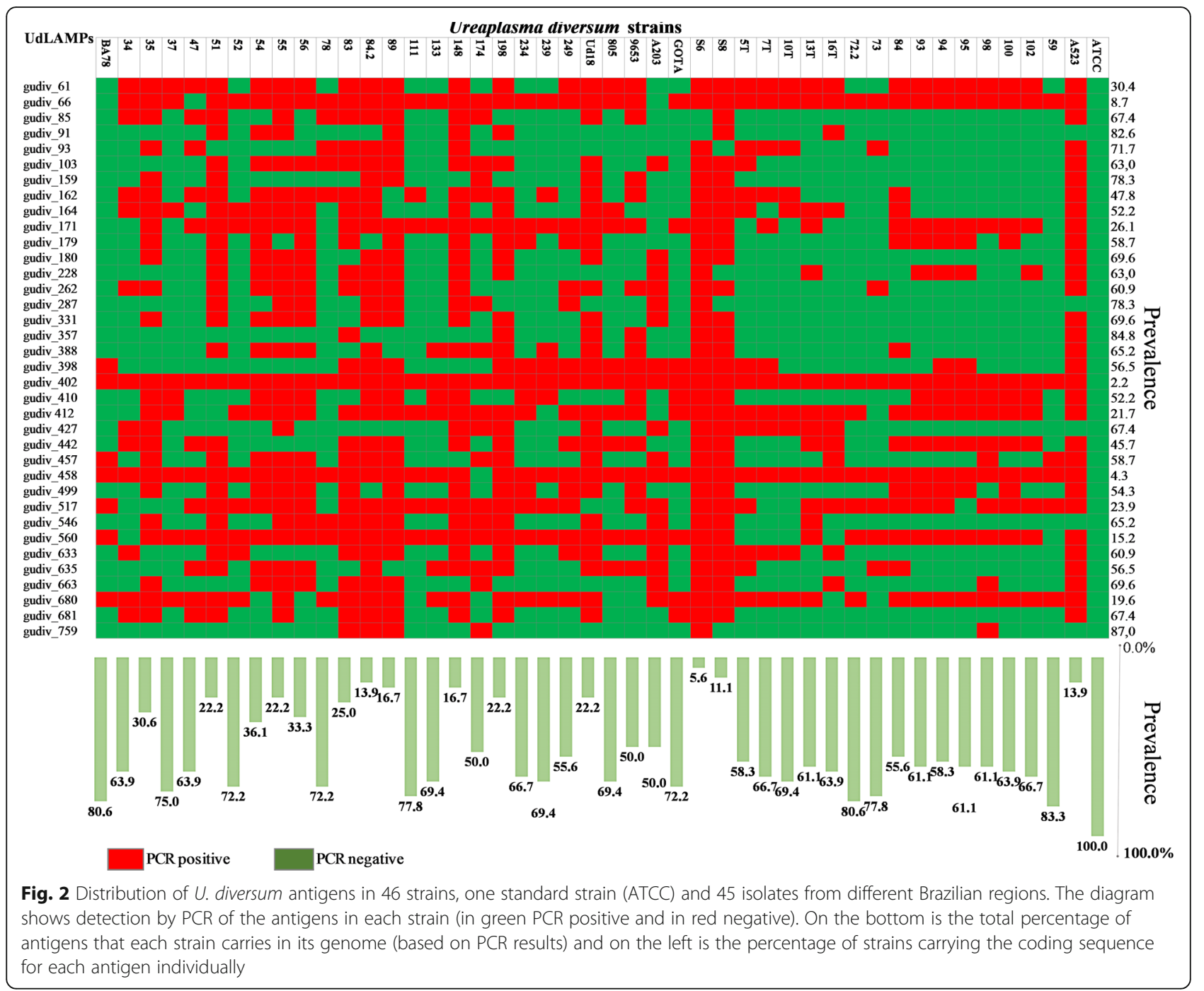

inclusion bodies [23]. Small peptides (about $10 \mathrm{kDa}$ ) are also difficult to express in stable form due to improper folding, so they are often subject to proteolytic degradation [24].

Our analyses also showed that only gudiv_93, gudiv 159, gudiv_331 and gudiv_560 had an instability index greater than 40 and, therefore, all the others (with an index below 40) were considered to be stable [25]. Most of the proteins were GRAVY negative, which is related to hydrophilicity [26]. Greater hydrophilicity implies a greater capacity to form hydrogen bonds with water molecules and, consequently, greater solubility [27]. Sixteen proteins were predicted to be soluble in the two predictors used in this work (Solpro and proteinSol) and only two proteins had more than two predicted transmembrane loops. Transmembrane loops are hydrophobic regions that reduce solubility [28]. Expression in the soluble form is desirable, because to obtain soluble proteins from insoluble forms, a series of processing steps that involves the use of strong denaturants followed by renaturation is inevitable [29]. Even so, these additional steps do not guarantee the production of soluble and functional proteins.

The presence of specific markers capable of directing heterologous peptides to the extracellular medium in an expression system also contributes to the subsequent steps in the production of recombinant proteins [23, 30, $31]$. Here, we show that more than half of the studied proteins were predicted to possess a SP recognized by sec/SPII and consequently likely a lipoprotein capable of being expressed and exported to the extracellular medium by E. coli. The presence of a SP for a classical secretory pathway or markers for secretion by a nonclassical pathway facilitates the transport and secretion of the transcript into the extracellular compartment. Secretion in the extracellular medium simplifies 


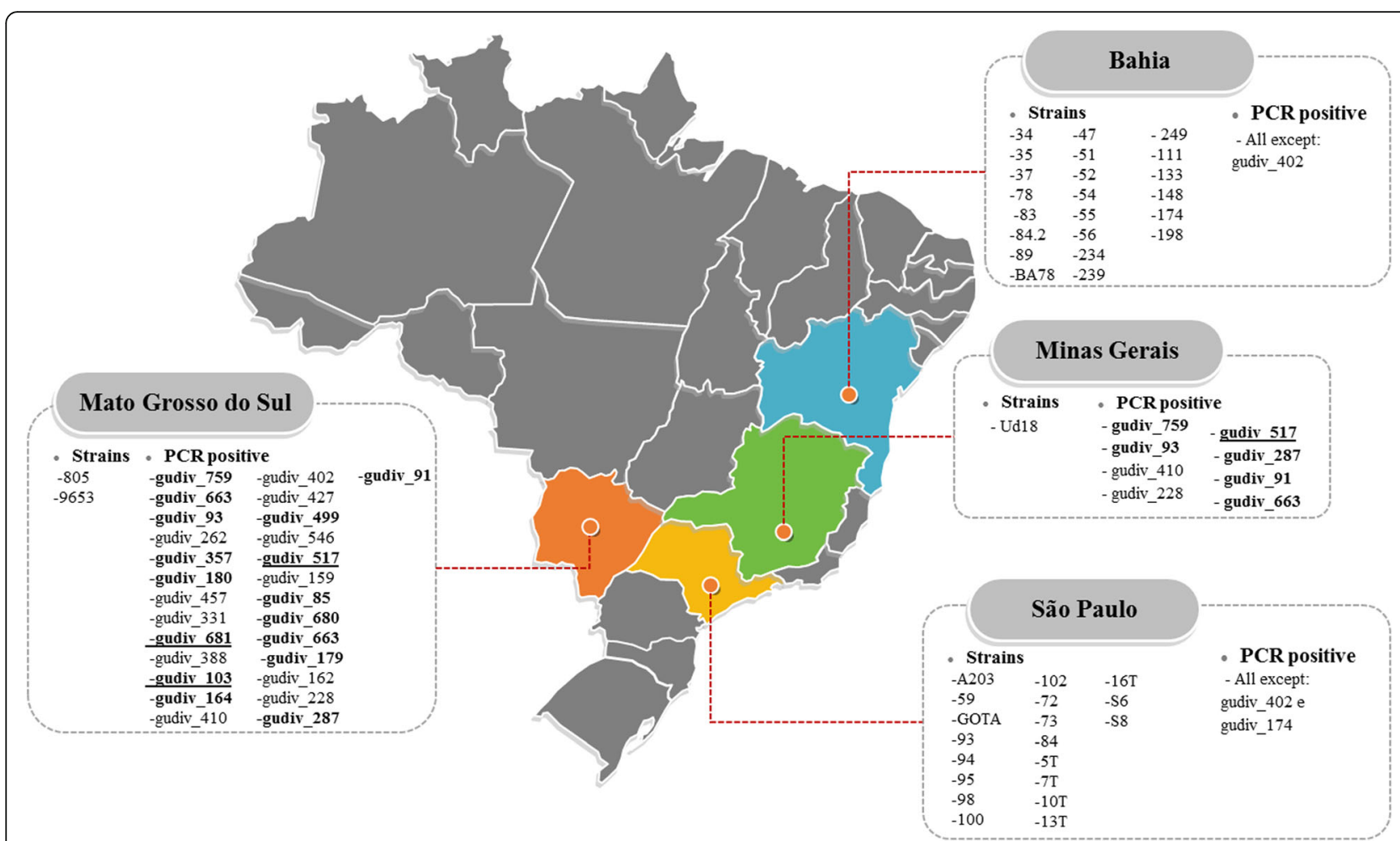

Fig. 3 Distribution of $U$. diversum antigens in different Brazilian states. The Brazilian states studied are represented in highlighted colors. In each state, the isolated strains and the set of UdLAMPs positive by PCR are used. In bold and underlined are UdLAMPs that (by prediction) showed good characteristics for immunological studies and expression in E. coli, not being retained in any of the exclusion criteria in Diagram 1. Only in bold, the antigens that, although they did not pass all criteria, were maintained in only one or two of the undesirable parameters for use in prophylactic and immunodiagnostic measures in Fig. 1. The figure was acquired at Wikimedia Commons (https://commons.wikimedia.org/wiki/ File:Brazil_Map-1.png) and was adapted using Adobe Photoshop CS6 version 13.0.6 ×64

purification processes, protects heterologous proteins from proteolysis, decreases endotoxin levels, and improves biological activity and solubility [32].

Bacterial proteins with good properties both for stimulating the immune response and for cloning and expression in a heterologous system are desirable targets for biotechnology [30]. In this study, the use of a filter with exclusion criteria based on the prediction data (In Diagram 1) showed that gudiv_61, gudiv_103, gudiv_517, and gudiv_681 are the ULAMPs most promising for immunobiological applications and for expression in E. coli as a heterologous system. However, the fact that an antigen does not meet all the requirements of Diagram 1 does not rule it out as a target for immunobiological studies or expression in a heterologous system. Depending on the type of analysis, proteins having good immunostimulatory properties, but with properties that hinder expression in E. coli could be expressed in other expression systems [33], or even in E. coli through fusion with proteins (tag) that increase the size of the transcript or improve solubility, reduce growth temperature, use of weak promoters and use of low concentrations of inducer [24]. Very large proteins or with many transmembrane loops could be studied by producing multiepitope chimeric proteins [34]. Finally, there is also the possibility of using expression systems entirely in vitro [35]. However, these alternatives increase the costs of the process; therefore, the inclusion of prediction in the planning stages of works that intend to express proteins can reduce project costs in addition to providing a theoretical forecast of bench tests.

In this work, the PCR detection of 36 UdLAMPs in isolates from $U$. diversum, from different regions of Brazil, warns of potential damage to livestock that $U$. diversum can cause, because in addition to immunomodulation, studies suggest that LAMPs are involved in adherence and invasion and cell apoptosis [2, 7, 15, 36]. Strains representing the four evaluated states (Bahia, Minas Gerais, São Paulo, and Mato Grosso do Sul) presented proteins with interesting properties for immunological stimulation (Diagrams 1 and 3). These data corroborate with other studies that show that $U$. diversum induces variable immune responses in vivo and in vitro [7, 37].

\section{Conclusion}

It was demonstrated that the $U$. diversum genome has CDS for molecules with potential for application in 
immunodiagnostic or immunoprophylactic tests and expression in E. coli as a heterologous system. PCR screening of antigens on strains from different states revealed that UdLAMPs have a heterogeneous distribution in different regions of Bahia, Minas Gerais, São Paulo, and Mato Grosso do Sul. In this study, 34 of the 36 UdLAMPs studied were noted in the genome as UdLAMPs and that many of them have signaling of typical lipoprotein secretion. It is well described in the literature that Mollicutes have ingenious molecular mechanisms to change parts of these molecules; however, this initial study contributes to understanding the virulence factors of $U$. diversum and provides a series of data and approaches that can be used in studying these pathogens.

\section{Methods}

Access to genes and analysis of similarity with bovine proteomes

The CDS and peptide sequences of 36 UdLAMPs, strain ATCC 49782, were accessed through the Manatee database (https://manatee.igs.umaryland.edu. The DNA sequences also are available in the GenBank: CP009770). Similarity analyses between proteins of $U$. diversum and proteomes of bovine subspecies (Bos taurus taurus, Bos taurus indicus and the hybrid Bos taurus x Bos indicus) were performed using the BLASTp tool accessed on the server https://www.ncbi.nlm.nih.gov. The proteomes were accessed on the BLASTp platform itself through the UniProtKB/Swiss-prot (swissprot) database under taxonomy IDs 9913 (Bos taurus taurus, protein count: 37513), 9915 (Bos taurus indicus, protein count 1243) and 30,522 (hybrid Bos taurus x Bos indicus, protein count: 42151).

\section{Mapping of B lymphocyte epitopes and antigenicity prediction}

The CBTOPE v1.0 server (available at http://crdd.osdd. net/raghava/cbtope/) was used to predict discontinuous (conformational) epitopes of B lymphocytes. A threshold of -0.3 was used, and on the probability scale (0-9) amino acids with values greater than four were considered conformational epitopes. This server has a data set with non-redundant protein chains consisting of antibody interacting residues of B cell epitopes [38]. To predict continuous epitopes, the primary protein sequences were analyzed in the BepiPred v2.0 software (http:// www.cbs.dtu.dk/services/BepiPred/), a predictor trained only with data, present in your internal database, from epitopes derived from crystallographic structures. Amino acids with thresholds greater than 0.5 were considered linear B cell epitopes [13]. The protein sequences were also submitted to the VaxiJen v2.0 server (http://www. ddg-pharmfac.net/vaxijen/VaxiJen/VaxiJen.html); this predictor allows classifying antigens without using the sequence alignment feature. All proteins predicted to score above thresholds (0.5) were classified as antigenic. The prediction of $\mathrm{B}$ cell epitopes and antigenicity was also performed for the Msp5 ESXA_MYCBO peptide from $A$. marginale accessed at NCBI under ID number AY527217.1.

\section{Mapping of TCD8 ${ }^{+}$lymphocyte epitopes and identity analysis with proteomes of other Mollicutes}

The prediction of binding to MHCI with peptide windows with 9 amino acids, was performed using the server NetBoLApan v1.0, accessed at http://www.cbs.dtu. $\mathrm{dk} /$ services/NetBoLApan/. A standard threshold of $0.5 \%$ was used for strong bonds and $2 \%$ for weak bonds; finally, the number of strong and weak connections were added and expressed in absolute numbers. The NetBoLApan v1.0 was trained on a peptide dataset with binding affinity to BoLA molecules [39]. The alleles used in this study were BoLA-6*01301 (HD6), BoLA-2*01201 (T2A), BoLA-3*00201 (JSP), BoLA-1*02301 (D18.4), BoLA-3*00101 (AW10), BoLA-6*04101 (T2B), BoLA$\mathrm{T} 2 \mathrm{C}$ and Bola-T5. In this set of alleles there are representatives of three bovine subspecies (Bos taurus taurus, Bos taurus indicus and the hybrid Bos taurus taurus $x$ Bos taurus indicus), thus including cattle involved in various livestock activities [17]. The same analyses were performed for Theileria parva Tp2 antigen.

The BLASTp was used for identity analysis of 36 UdLAMPs with proteomes of $M$. bovis (831 protein count and taxonomy IDs: 28903), M. canadense (481 protein count and taxonomy IDs: 29554), M. bovigenitalium (677protein count and IDs taxonomy: 1188235), $M$. bovirhinis (720 protein count and taxonomy IDs: 29553), and $M$. dispar (712 protein count and taxonomy IDs: 86660).

\section{Prediction of secretion and subcellular localization}

Prediction of classical secretion and identification of SP were performed on the SignalP v5.0 server available at http://www.cbs.dtu.dk/services/SignalP/ and DOLOP, a server that uses SP characteristics to predict lipoproteins -https://www.mrc-lmb.cam.ac.uk/genomes/dolop/. The SecretomeP v2.0 web server (http://www.cbs.dtu.dk/services/SecretomeP) was used to predict non-classical secretion. Predicted values equal to or greater than 0.5 (threshold) were considered indicative of secretion. Protein sequences were also subjected to the prediction of subcellular location in the PSORTb v3.0.2 software (http://www.psort.org/psortb/) using suggested settings for Mycoplasma spp. TMHMM v2.0 (http://www.cbs. $\mathrm{dtu}$.dk/services/TMHMM/) was used to verify the presence of transmembrane loops. 


\section{Investigation of physical-chemical parameters}

The physicochemical properties of UdLAMPs including aliphatic index, PM, GRAVY, and instability index were obtained in ProtParam using the ExPASy server at http://web.expasy.org/protparam/. The solubility of heterologous peptides after $E$. coli overexpression was predicted by the server SOLpro (http://scratch.proteomics.ics.uci.edu/) and Protein-Sol, accessed at https:// protein-sol.manchester.ac.uk/.

\section{Filter properties related to immunomodulation and expression in a heterologous system}

$U$. diversum antigens were classified according to two parameters: 1) Undesirable parameters for use in prophylactic and immunodiagnostic measures; in which prediction results for similarity with bovine proteomes were evaluated, number of conformational and continuous epitope regions for B lymphocytes, antigenicity, number of $\mathrm{T}$ lymphocyte epitopes (BoLA allele ligands) and identity with other Mollicutes that infect cattle; 2) undesirable parameters for expression in E. coli; in which predicted parameters related to the absence of signaling for excretion by classical or non-classical pathways, protein size, stability index, GRAVY, solubility and presence of transmembrane loops were evaluated.

\section{Obtaining, cultivating and extracting DNA from $U$. diversum}

$U$. diversum ATCC 49782 and 45 isolates were provided by the Mycoplasma laboratory of the Institute of Biomedical Sciences - University of São Paulo (USP). Some strains were isolated from cows that had granulomatous vulvovaginitis, and others were isolated from the semen of healthy bulls. The isolates were obtained from four states: 19 isolated in São Paulo (farms 1, 2, 4, 8 and 9), 2 isolated in Mato Grosso do Sul (farm 3), 1 in Minas Gerais (farm 6), and 22 in Bahia (farms 10, 11, 12, 13). One milliliter of each sample previously-stored in UB medium was grown in $9 \mathrm{ml}$ of the same medium at $37^{\circ} \mathrm{C}$ for 24 to $48 \mathrm{~h}$ [7]. After growth, bacterial DNA was extracted using the NucleoSpin kit (Macherey-Nagel, Germany) following the manufacturer's instructions. After growth, bacterial DNA was extracted using the NucleoSpin kit (Macherey-Nagel, Germany) following the manufacturer's instructions.

\section{Primer construction, PCR, and electrophoresis}

The genomic sequences coding for the 36 antigens of $U$. diversum were used to design the primers by the servers https://www.idtdna.com/calc/analyzer and https://www. bioinformatics.org/sms/revcomp.html. Important criteria for the efficiency of primers such as size (18 to $22 \mathrm{bp}$ ), melting temperature $\left(52\right.$ to $58^{\circ} \mathrm{C}$ ), and $\mathrm{G}+\mathrm{C}$ content (40 to $60 \%$ ) were taken into account. After selecting the best pairs of primers, similarity analysis was performed by the BLASTn server (https://blast.ncbi.nlm.nih.gov/ Blast.cgi) to confirm the specificity of the primer sequence for $U$. diversum. The 46 strains were evaluated for the presence of genes for UdLAMPs using PCR. The amplifications were performed with a total volume of $25 \mu \mathrm{l}$ containing: $1 \mu \mathrm{l}$ of DNA, 10x PCR buffer $(10 \mathrm{mM}$ Tris - $\mathrm{HCl}, \mathrm{pH} 9.0 ; 50 \mathrm{mM} \mathrm{KCl}), 1.5 \mathrm{mM} \mathrm{MgCl}$; $200 \mu \mathrm{M}$ dNTP, $50 \mathrm{pmol}$ of each primer and $1.5 \mathrm{U}$ of Taq DNA polymerase (Invitrogen ${ }^{\circ}$, Brazil). All genes followed the initial denaturation of $94^{\circ} \mathrm{C}$ for $5 \mathrm{~min}$, followed by 35 thermal cycles of $94{ }^{\circ} \mathrm{C}$ for $30 \mathrm{~s}, 54{ }^{\circ} \mathrm{C}$ for $30 \mathrm{~s}$, and $72{ }^{\circ} \mathrm{C}$ for one minute, concluding with a final extension $72{ }^{\circ} \mathrm{C}$ for $5 \mathrm{~min}$. The reaction products were analyzed by electrophoresis on $1.5 \%$ agarose gel, stained with $2.5 \mu \mathrm{l}$ ethidium bromide $(10 \mathrm{mg} / \mathrm{ml})$, visualized and photographed under UV light. A molecular weight marker (Invitrogen ${ }^{\oplus}$, Brazil) - was used as a standard to assess the size of the amplified fragments.

\section{Supplementary information}

Supplementary information accompanies this paper at https://doi.org/10 1186/s12917-020-02602-1.

Additional file 1: Table S1. Sequences of the most significant B lymphocyte epitopes (highest thresholds in the Pepipred 2.0 predictor) accompanied by the position of the respective epitope in each UdLAMP.

Additional file 2: Table S2. Sequence of the most representative CD8+ $\mathrm{T}$ lymphocyte epitopes and respective position in each UdLAMP predicted using NetBoLApan v1.0. Peptides with an 8-amino acid window of the BoLA- $1{ }^{*} 02301$, BoLA- $3 * 00201$, BoLA- $2{ }^{*} 01201$ and BoLA- $6{ }^{*} 01301$ alleles are represented.

Additional file 3: Table S3. Sequence of the most representative CD8+ $\mathrm{T}$ lymphocyte epitopes and respective position in each UdLAMP predicted using NetBoLApan v1.0. Peptides with an 8-amino acid window of the BoLA-3 ${ }^{*} 00101$, BoLA-4 ${ }^{*} 04101$, BoLA-T2C, and BoLA-T5 alleles are represented.

\section{Abbreviations}

Aa: Amino acids; ATCC: American Type Culture Collection; BoLA: Bovine lymphocyte antigen; CDS: Gene coding sequences; dNTP: Deoxynucleotides; G +C: Guanine-cytosine content; GRAVY: Grand average of hydropathy; IgG: Immunoglobulin G; KDa: Kilodalton; LAMP: Lipid-associated membrane protein; MBA: Multiple band antigen; $\mathrm{MHCl}$ : Major histocompatibility complex class I; MIB: Mycoplasma lg binding protein; MIP: Mycoplasma lg protease; Msp5: Surface protein 5 from A. marginale; PCR: Polymerase Chain Reaction; PM: Molecular weight; SP: Signal peptide; Tp2: T. parva 2 antigen; UB: Ureaplasma base; UdLAMPs: Lipid-associated membrane protein of $U$. diversum

\section{Acknowledgements}

We also thank Aricelma P. França for invaluable technical assistance and Jim Hesson of Academic English Solutions (academicenglishsolutions.com) for revising the English.

\section{Authors' contributions}

Conceived and designed the experiments: MNSJ, GBC, BLB, JT and LMM. Immunoinformatics analysis: MNSJ, RSS, WSN, BCBG, MSB, LSCS, CPG, ISR. Molecular analysis: MNSJ, JMF, CNTO, ISR, NSMN. Analyzed the data: MNSJ, GBC, BLB, GBC, JT and LMM. Contributed reagents/materials/analysis tools: GBC, BLB, JT and LMM. Wrote the paper: MNSJ, GBC, JT and LMM. All authors read and approved the final manuscript. 


\section{Funding}

This work was supported by grants from the São Paulo Research Foundation (FAPESP) (grant number 2017/25686-3), the National Council for Scientific and Technological Development (CNPq) (grant number 409758/2018-3) and Coordenação de Aperfeiçoamento de Pessoal de Nível Superior - Brasil (CAPES) (Finance Code 001). The funders played no role in the design as well as conclusion of the study.

\section{Availability of data and materials}

The DNA sequences generated and/or analyzed during the current study are available in the GenBank repository, Accession: CP009770. The others datasets used and/or analyzed during the current study are available from the corresponding author on reasonable request.

\section{Ethics approval and consent to participate}

Not applicable.

\section{Consent for publication}

Not applicable.

\section{Competing interests}

The authors declared no potential conflicts of interest with respect to the research, authorship, and/or publication of this article.

\section{Author details}

${ }^{1}$ Department of Biointeraction, Multidisciplinary Institute of Health, Universidade Federal da Bahia, Rua Hormindo Barros, 58 - Quadra 17 - Lote 58, Bairro Candeias - CEP: 45.029-094, Vitória da Conquista, BA, Brazil. 2Department of Microbiology, State University of Santa Cruz (UESC), Ilhéus, Brazil. ${ }^{3}$ Department of Microbiology, Institute of Biomedical Science, University of São Paulo, São Paulo, Brazil.

Received: 8 July 2020 Accepted: 30 September 2020

Published online: 07 October 2020

\section{References}

1. Marques LM, Buzinhani M, Oliveira RC, Yamaguti M, Ferreira JB, Neto RL, et al. Prevalence of mycoplasmas in the respiratory tracts of calves in Brazil. Vet Rec. 2007;161(20):699-700.

2. Marques LM, Rezende IS, Barbosa MS, Guimarães AM, Martins HB, Campos $G B$, et al. Ureaplasma diversum genome provides new insights about the interaction of the surface molecules of this bacterium with the host. PLoS One. 2016;11(9):e0161926.

3. Cardoso MV, Scarcelli E, Grasso LM, Teixeira SR, Genovez ME. Ureaplasma diversum and reproductive disorder in Brazilian cows and heifers; first report. Anim Reprod Sci. 2000;63(3-4):137-43.

4. Gourlay RN, Howard CJ, Brownlie J. The production of mastitis in cows by the intramammary inoculation of T-mycoplasmas. J Hyg (Lond). 1972;70(3): 511-21.

5. Marques LM, Buzinhani M, Guimaraes AM, Marques RC, Farias ST, Neto RL, et al. Intraspecific sequence variation in 16S rRNA gene of Ureaplasma diversum isolates. Vet Microbiol. 2011;152(1-2):205-11.

6. Crane MB, Hughes CA. Can Ureaplasma diversum be transmitted from donor to recipient through the embryo? Two case reports outlining $U$. diversum losses in bovine embryo pregnancies. Can Vet J. 2018;59(1):43.

7. Santos-Junior MN, Rezende IS, Souza CLS, Barbosa MS, Campos GB, Brito LF, et al. and Its Ureaplasma diversum and Its Membrane-Associated Lipoproteins Activate Inflammatory Genes Through the NF-kB Pathway via Toll-Like Receptor 4. Front Microbiol. 2018;9:1538.

8. Marques LM, Guimarães AM, Martins HB, Rezende IS, Barbosa MS, Campos $\mathrm{GB}$, et al. Genome sequence of Ureaplasma diversum strain ATCC 49782 Genome Announc. 2015;3(2):e00314-5.

9. Zhang C, Marcia M, Langer JD, Peng G, Michel H. Role of the N-terminal signal peptide in the membrane insertion of a quifex aeolicus F1F0 ATP synthase c-subunit. FEBS J. 2013;280(14):3425-35.

10. da Rocha Sobrinho HM, Jarach R, da Silva NA, Shio MT, Jancar S, Timenetsky $J$, et al. Mycoplasmal lipid-associated membrane proteins and mycoplasma arthritidis mitogen recognition by serum antibodies from patients with rheumatoid arthritis. Rheumatol Int. 2011;31(7):951-7.
11. Hara Y, Mohamed R, Nathan S. Immunogenic Burkholderia pseudomallei outer membrane proteins as potential candidate vaccine targets. PLoS One. 2009;4(8):e6496.

12. Gutlapalli VR, Sykam A, Nayarisseri A, Suneetha S, Suneetha LM. Insights from the predicted epitope similarity between mycobacterium tuberculosis virulent factors and its human homologs. Bioinformation. 2015;11(12):517-24.

13. Jespersen MC, Peters B, Nielsen M, Marcatili P. BepiPred-2.0: improving sequence-based B-cell epitope prediction using conformational epitopes. Nucleic Acids Res. 2017;45(W1):W24-W9.

14. Corona B, Machado H, Rodríguez M, Martínez S. Characterization of recombinant MSP5 Anaplasma marginale Havana isolate. Braz J Microbiol. 2009;40(4):972-9.

15. Buzinhani M, Yamaguti M, Oliveira RC, Cortez BA, Marques LM, MachadoSantelli GM, et al. Invasion of Ureaplasma diversum in bovine spermatozoids. BMC Res Notes. 2011:4:455.

16. Pelle R, Graham SP, Njahira MN, Osaso J, Saya RM, Odongo DO, Toye PG, Spooner PR, Musoke AJ, Mwangi DM, Taracha EL, Morrison WI, Weir W, Silva JC, Bishop RP. Two Theileria parva CD8 T cell antigen genes are more variable in buffalo than cattle parasites, but differ in pattern of sequence diversity. PLoS One. 2011;6(4):e19015. https://doi.org/10.1371/journal.pone. 0019015.

17. Hansen AM, Rasmussen M, Svitek N, Harndahl M, Golde WT, Barlow J, et al. Characterization of binding specificities of bovine leucocyte class I molecules: impacts for rational epitope discovery. Immunogenetics. 2014; 66(12):705-18

18. Teodoro RL, Martinez ML, Silva M, Machado MA, Verneque R. Resistência bovina ao carrapato Boophilus microplus: experiência brasileira. In: Anais do $\checkmark$ Simpósio da Sociedade Brasileira de Melhoramento Animal, Pirassununga, SBMA; 2004.

19. Yisehak K, Becker A, Belay D, Bosch G, Hendriks WH, Clauss M, et al. Salivary amino acid concentrations in zebus (Bos indicus) and zebu hybrids (Bos indicus $\times$ Bos taurus) fed a tannin-rich diet. Belgian J Zool. 2011;141(2):93-6.

20. Rost B. Twilight zone of protein sequence alignments. Protein Eng. 1999; 12(2):85-94.

21. Khan FA, Faisal M, Chao J, Liu K, Chen X, Zhao G, et al. Immunoproteomic identification of MbovP579, a promising diagnostic biomarker for serological detection of mycoplasma bovis infection. Oncotarget. 2016;7(26): 39376.

22. Chang CCH, Song J, Tey BT, Ramanan RN. Bioinformatics approaches for improved recombinant protein production in Escherichia coli: protein solubility prediction. Brief Bioinform. 2014;15(6):953-62.

23. Adrio J-L, Demain AL. Recombinant organisms for production of industrial products. Bioengineered Bugs. 2010;1(2):116-31.

24. Sørensen HP, Mortensen KK. Advanced genetic strategies for recombinant protein expression in Escherichia coli. J Biotechnol. 2005;115(2):113-28.

25. Gasteiger E, Hoogland C, Gattiker A, Duvaud S, Wilkins MR, Appel RD, et al., Protein identifica-tion and analysis tools on the ExPASy server, in The Proteomics Protocols Handbook. Walker JM Ed., Totowa: Humana Press; 2005.

26. Vandahl BB, Christiansen G, Birkelund S. Preparation of bacterial samples for 2D-PAGE; in The proteomics protocol handbook. JM Walker (ed). Totowa: Humana press Inc.; 2005. p. 19-27.

27. Negahdaripour M, Nezafat N, Hajighahramani N, Soheil Rahmatabadi S, Hossein Morowvat M, Ghasemi Y. In silico study of different signal peptides for secretory production of interleukin-11 in Escherichia coli. Current Proteomics. 2017;14(2):112-21.

28. Käll L, Krogh A, Sonnhammer EL. A combined transmembrane topology and signal peptide prediction method. J Mol Biol. 2004;338(5):1027-36.

29. Singh SM, Panda AK. Solubilization and refolding of bacterial inclusion body proteins. J Biosci Bioeng. 2005;99(4):303-10.

30. Chaudhry R, Nisar N, Hora B, Chirasani SR, Malhotra P. Expression and immunological characterization of the carboxy-terminal region of the P1 adhesin protein of mycoplasma pneumoniae. J Clin Microbiol. 2005;43(1): $321-5$.

31. Rosano GL, Ceccarelli EA. Recombinant protein expression in Escherichia coli: advances and challenges. Front Microbiol. 2014;5:172.

32. Mohammadi S, Mostafavi-Pour Z, Ghasemi Y, Barazesh M, Pour SK, Atapour A, et al. In silico analysis of different signal peptides for the excretory production of recombinant NS3-GP96 fusion protein in Escherichia coli. Int J Pept Res Ther. 2019:25(4):1279-90. 
33. Kaur J, Kumar A, Kaur J. Strategies for optimization of heterologous protein expression in E. coli: Roadblocks and reinforcements. Int J Biol Macromol. 2018;106:803-22.

34. AnandaRao R, Swaminathan S, Fernando S, Jana AM, Khanna N. A customdesigned recombinant multiepitope protein as a dengue diagnostic reagent. Protein Expr Purif. 2005;41(1):136-47.

35. Popot JL. Amphipol-Assisted Cell-Free Expression of Membrane Proteins. In: Membrane Proteins in Aqueous Solutions. Biological and Medical Physics, Biomedical Engineering. Cham: Springer; 2018. https://doi.org/10.1007/9783-319-73148-3_7.

36. Hobson N, Chousalkar KK, Chenoweth PJ. Ureaplasma diversum in bull semen in Australia: its detection and potential effects. Aust Vet J. 2013; 91(11):469-73.

37. Gaeti JG, Lana MV, Silva GS, Lerner L, de Campos CG, Haruni F, et al. Ureaplasma diversum as a cause of pustular vulvovaginitis in bovine females in Vale Guapore, Mato Grosso state, Brazil. Trop Anim Health Prod. 2014:46(6):1059-63.

38. Ansari HR, Raghava GP. Identification of conformational B-cell epitopes in an antigen from its primary sequence. Immunome Res. 2010;6(1):6.

39. Nielsen M, Connelley T, Ternette N. Improved prediction of bovine leucocyte antigens (BoLA) presented ligands by use of mass-spectrometrydetermined ligand and in vitro binding data. J Proteome Res. 2018;17(1): $559-67$

\section{Publisher's Note}

Springer Nature remains neutral with regard to jurisdictional claims in published maps and institutional affiliations.

Ready to submit your research? Choose BMC and benefit from:

- fast, convenient online submission

- thorough peer review by experienced researchers in your field

- rapid publication on acceptance

- support for research data, including large and complex data types

- gold Open Access which fosters wider collaboration and increased citations

- maximum visibility for your research: over $100 \mathrm{M}$ website views per year

At BMC, research is always in progress.

Learn more biomedcentral.com/submissions 